\title{
Paisajes culturales como imágenes de destino: percepción y valoración como producto turístico
}

\author{
M. Violante Martínez Quintana* \\ Universidad Nacional de Educación a Distancia UNED (España)
}

M. Victoria Sanagustín Fons**

Universidad de Zaragoza (España)

Rocío Blanco Gregory****

Universidad de Extremadura (España)

\begin{abstract}
Resumen: Los paisajes culturales se han convertido en productos turísticos que, dependiendo de la imagen de destino proyectada, ejercen una importante atracción del turismo cultural y de naturaleza. Este potencial es objeto de estudio actualmente, y los de imágenes de destino pertenecen a una literatura extensa en ciencias sociales. La unión de paisajes culturales e imágenes de destino se ha situado en las primeras filas de investigación, este trabajo aporta conocimiento sobre la percepción y valoración que de ellos se tienen. Se indaga la percepción y valoración de los paisajes culturales e imágenes de destino a una muestra de turistas entre las Comunidades Autónomas, y un Panel de Experto para averiguar en el caso de Toledo, los componentes de la imagen de destino turística, las posibilidades del paisaje como producto turístico en sí mismo y diferenciado, las estrategias para su desarrollo turístico, y la promoción y difusión de los paisajes culturales ${ }^{1}$.
\end{abstract}

Palabras Clave: Paisajes culturales; Imágenes de destino; Producto turístico; Percepción de la imagen; Valoración de la imagen.

\section{Cultural landscapes as images of destination: perception and valuation as tourist product}

Abstract: Cultural landscapes have become tourism products that, depending on the image of the intended destination, exert an important attraction of cultural tourism and quality nature. This potential is currently under study, and those of destination images belong to an extensive literature in social sciences. The union of cultural landscapes and images of destination has been placed in the first lines of research, so this work is an attempt to contribute knowledge with respect to perception and value for sustainable tourism development. Therefore, the perception and valuation of the cultural landscapes and images of a destination have been tested with a sample of tourists from a broad range of Autonomous Communities, and an Expert Panel to investigate, in the case of Toledo, the components of the tourist destination image, the possibilities of differentiated landscape as a tourism product in itself, the strategies for its tourism development, and the promotion and dissemination of cultural landscapes.

Keywords: Cultural landscapes; Destination images; Tourist product; Perception of image; Valuation of timage.

\section{Introducción}

La dinámica evolutiva de los paisajes culturales en el turismo es un área de estudio que ha abierto bastantes líneas de investigación en el urbanismo de las ciudades, las áreas metropolitanas, las ciudades

* Profesora Titular de Sociología, Departamento Sociología III(Tendencias Sociales); Universidad Nacional de Educacion a Distancia UNED (Espana); E-mail: vmartin@poli.uned.es

** Profesora Titular de Sociología, Departamento de Psicología y Sociología; Universidad de Zaragoza; E-mail: vitico. sanagustin@gmail.com

*** Profesor Contratado Doctor, Departamento de Dirección de Empresas y Sociología; Universidad de Extremadura; E-mail: rblanco@unex.es 
históricas, los pueblos y sus paisajes, y el ocio moderno. En esta trayectoria se enfatiza las tendencias que marcan los resultados de las encuestas de organismos públicos y otras fuentes, entre los que destacan los sitios y los lugares de especial valor natural y cultural, de carácter histórico, es decir, los paisajes culturales (Zárate, 2012). La forma urbana y sus paisajes se conforman en símbolos de identificación social y en recursos susceptibles de generar riqueza, así como la necesidad de mantenerlos y conservarlos.

La defensa de los paisajes, en general, y de los valores patrimoniales, en particular, se consolida a través de la Carta Internacional para la Conservación de las Ciudades Históricas y las Áreas Urbanas de 1987 (Carta de Toledo-Washington). Asimismo, la Carta Internacional del Turismo sobre turismo cultural en la que se gestiona el turismo en los sitios con Patrimonio Significativo (1999), y la Convención Europea del Paisaje del año 2000 (Florencia), introducen la conservación del paisaje en el urbanismo y la ordenación del territorio, y estimula la puesta en valor del paisaje como elemento creador de riqueza a través del turismo.

La Declaración de Xi'an de 2005 alude a la conservación del entorno de las estructuras, de los lugares y de las áreas patrimoniales, la Recomendación del Comité de ministros a los Estados miembros del Consejo de Europa con el Convenio Europeo del Paisaje (6 de febrero de 2008) y, por último, las orientaciones de la Unesco (2012) se dirigieron a la conservación de los entornos urbanos y a la puesta en valor de los paisajes culturales, entre los que se incluye el turismo.

La Comisión Europea adopta en marzo de 2006 una nueva política turística encaminada a mejorar la competitividad de la industria del turismo para crear más y mejores empleos a través de un crecimiento sostenible del turismo en Europa. A partir de ahí surge la Agenda 21 europea para el turismo basada en la Sostenibilidad del Turismo, que se presenta en un informe en febrero de 2007 (Action for more sustainable European tourism). Se activa, por tanto, una intensa interacción entre el entorno y la sociedad basada en las sinergias del desarrollo de destinos turísticos relacionado con su entorno natural, sus especificidades culturales, su interacción social, su seguridad y el bienestar de las poblaciones locales (Sanagustín et al., 2011).

La Carta Internacional sobre Turismo Cultural (La Gestión del Turismo en los sitios con patrimonio significativo, Icomos, 1999) representa un hito en la contemplación y toma de consideración en los patrimonios naturales y culturales, e insta a los pueblos al derecho y responsabilidad de comprenderlos y conservarlos como valores universales. El patrimonio se configura en un compendio de entornos naturales y culturales que incorpora los paisajes, los sitios históricos, los emplazamientos, los entornos construidos, la biodiversidad, los grupos de objetos diversos, las tradiciones pasadas y presentes y, por último, los conocimientos y experiencias vitales.

Los destinos turísticos que oferten aspectos culturales a través de sus recursos históricos y artísticos con sus entornos naturales y paisajísticos, son los que entran en la modalidad de turismo alternativo y de las nuevas demandas en ocio y turismo en la actualidad. La cultura es el núcleo central, y sus estancias oscilan entre los 3 y 4 días, siendo las ciudades históricas la fuente de atracción principal con todos los monumentos, paisajes, infraestructuras urbanísticas reconstruidas y las áreas urbanas de ocio y recreación colindantes a ellas.

\section{Definición de paisajes culturales y vínculo con imágenes de destino}

Los paisajes culturales han sido definidos como el resultado de la interacción en el tiempo de las personas y el medio natural, cuya expresión es un territorio percibido y valorado por sus cualidades culturales, que, a su vez, es producto de un proceso y soporte de la identidad de una comunidad. Constituye, por tanto, una realidad dinámica, compleja y de difícil gestión (Ministerio de Educación, Cultura y Deporte, 2012). Estos recursos forman parte del denominado turismo cultural que es definido como aquel viaje motivado por conocer, comprender y disfrutar el conjunto de rasgos y elementos distintivos, espirituales y materiales, intelectuales y afectivos que caracterizan a una sociedad o grupo social de un destino específico (Sectur-Cestur, 2002). Los efectos que genera engloban la satisfacción del cliente, la conservación del patrimonio de uso turístico, y el desarrollo económico y social de las comunidades a partir de la generación de nuevos empleos.

En la European Landscape Convention, el paisaje cultural se define como cualquier parte de un territorio y la manera en que es percibido por la población. La importancia del carácter que emana del paisaje es básica, ya que es fruto del resultado de la acción y de la interacción de los factores naturales y humanos que ahí han intervenido. Independientemente de la cualidad estética del paisaje, se halla circunscrito a un entorno natural de una comunidad determinada.

El vínculo que se establece entre paisajes culturales con imágenes de destino viene determinado, en gran parte, por el determinismo de las páginas webs que ofrecen en sus portales títulos atrayentes y sugestivos. De manera que los paisajes culturales se circunscriben en imágenes de destino para ser conocidos y percibidos, experimentados y plasmados en diversas conductas turísticas. Aquí es donde 
entran a formar parte del proceso la percepción y valoración de los turistas para decidir aquel destino en función de las impresiones recibidas de las imágenes proyectadas.

En la literatura sobre la imagen de destino y los mecanismos que ahí tienen lugar se obtiene que la imagen global del destino influye no sólo en el proceso de selección del destino, sino también en la conducta del turista en general. La importancia de la lealtad radica en que es más difícil y más caro atraer a nuevos clientes que retener los ya existentes (Rosemberg and Czepiel, 1984). Por tanto, la imagen de destino es fundamental, ya que tiene un impacto positivo en el valor percibido, la calidad, la satisfacción y la intención de conducta (Chen and Tsai, 2007). En el mismo sentido, Bigné, Sánchez y Sánchez (2001) concluyen que la imagen de destino afecta a la lealtad tanto directa como indirectamente.

Otros especialistas han mostrado que en esta percepción de la imagen, la satisfacción que se obtiene de los atributos de la imagen de destino tiene una influencia positiva en la intención de volver a visitar el lugar (lealtad, fidelización), y en la intención de recomendar el destino (Kozark and Rimmington, 2000; Campo and Garau, 2008; Chi and Qu, 2008). De aquí que la experimentación satisfactoria que se obtiene tras la percepción y valoración positiva, incide favorablemente en una fidelización del turista.

Por último, el componente conativo (conductual) que Pike and Ryan (2004) y Lin et al. (2007) han trabajado en sus investigaciones, da cuenta de la intención de conducta como una consecuencia de los dos componentes anteriores, es decir, de la imagen de destino y su impacto positivo o negativo, y de la satisfacción que se obtiene en la experiencia turística. Es el componente activo de la actitud, es decir, la tendencia a reaccionar en la estancia misma de la visita, en la vuelta al lugar visitado y en la recomendación de la misma. En definitiva, el mecanismo o proceso que tiene lugar en la elaboración de la imagen de destino de los paisajes culturales tiene tres componentes para la formación de la actitud hacia la misma (Pike and Ryan, 2004; Tasci, Gartner and Cavusgil, 2007), a saber:

1) El componente cognitivo o perceptual: se refiere al conocimiento y a las creencias que se tienen sobre los atributos del destino.

2) El componente afectivo: es emotividad, y da cuenta de las emociones y sentimientos del turista hacia el destino. Es una valoración emocional positiva o negativa, asociada a lo agradable o desagradable.

3) El componente conativo (conductual): se refiere a la intención de conducta como una consecuencia de los dos componentes anteriores.

El componente cognitivo de la imagen es un predictor directo de la revisita (lealtad, fidelización) del destino, y de las intenciones de recomendar ese destino. En otros estudios es un predictor indirecto a través de la satisfacción global con los atributos del destino (Bigné, Sanchez and Sanchez, 2001; Chi and $\mathrm{Qu}, 2008)$. El destino que tenga una imagen más positiva, más probable será que se incluya en el proceso de toma de decisiones. En definitiva, tal y como afirman Fornell et ali., 1990 y Kozak and Rimmington, 2000, la imagen de destino afecta a la calidad percibida y a la satisfacción, ya que la satisfacción es el resultado de la evaluación de la calidad percibida.

\section{Objetivos del estudio}

Según las perspectivas de desarrollo que presentan los paisajes culturales y sus imágenes de destino como producto turístico en España, nuestro estudio pretende contribuir al acercamiento y conocimiento de dos realidades que deben ser estudiadas y analizadas, de cara a la planificación turística en el sector. Una primera realidad general atiende a indagar la percepción y valoración de los paisajes culturales como producto turístico, y una segunda realidad más concreta sobre los componentes de la imagen turística, las posibilidades del paisaje como producto turístico en sí mismo y diferenciado, las estrategias para su desarrollo y la promoción de los paisajes culturales en una ciudad emblemática como la de Toledo. Los resultados podrán contribuir a diseñar los elementos básicos de las estrategias de desarrollo y promoción en la puesta en valor de los paisajes culturales como imágenes de destino, que sean capaces de generar riqueza económica y social en los territorios y poblaciones, así como proteger y mantener el patrimonio histórico artístico y natural, con los que se identifican como producto único y diferenciado.

\section{Metodología y plan de trabajo}

En la primera realidad general el presente trabajo ha diseñado una investigación cuantitativa mediante encuesta, con un cuestionario de 26 preguntas (abiertas, cerradas, mixtas, y de escala). La información obtenida se obtuvo mediante la realización de un total de 500 encuestas telefónicas realizadas 
dentro del ámbito español. Para concretar adecuadamente la muestra, la información a recoger y los resultados a obtener, el universo se delimitó a personas mayores de 18 años que viven en municipios de más de 20.000 habitantes en las comunidades autónomas, y que han visitado en los últimos tres años alguna ciudad monumental o ciudad histórica, durante los meses de abril y mayo de 2014 (error muestral +/- 4,47\%, bajo el supuesto de muestreo probabilístico, nivel de confianza 95,5\%; $p=q=0,5$ ). Las técnicas de análisis de la información se han basado en técnicas descriptivas univariables (frecuencias y medias) a través de la confección de figuras y tablas. La encuesta contiene preguntas relacionadas con el componente cognitivo o perceptual, el afectivo o emocional y el conativo o de conducta.

El turista de la muestra tiene un perfil que le caracteriza por ser más exigente y crítico, utiliza Internet y redes sociales, dispone de una gran cantidad de información y opiniones sobre los destinos turísticos, y tiene poder de decisión dependiendo de la edad, el sexo y el nivel de estudios principalmente. Le gusta relajarse y desconectar, y al mismo tiempo interesarse por el entorno natural y paisajístico, y por la riqueza cultural (artes, rutas e itinerarios y turismo urbano) del destino turístico (Instituto de Turismo de España, 2014). También se añade el perfil del turista interno (Familitur, 2012) que tiene un componente de género, ya que los varones realizan más viajes que las mujeres. Respecto a la edad, los viajeros con edades comprendidas entre los 25 y 44 años son los que más viajes realizan, y a mayor nivel de formación mayor es el número de viajes por individuo. La estancia media aumenta a partir de los 65 años, dada la mayor disponibilidad de tiempo libre para viajar.

Los especialistas han tipificado tres turistas culturales, el cultural preparado, el cultural fortuito, el cultural superficial y el reacio a la cultura. MacKercher y Du Cros (2002) incorporan más matices con la dimensión de la experiencia profunda en el turista cultural en función de la importancia que se concede a la cultura en la elección de un destino, y puede ser de importancia básica o de importancia elevada. Todo ello dentro del turismo cultural que se ha convertido en un producto estrella y con tendencia al alza (Richards, 2011).

El imaginario del turista pone en funcionamiento un proceso basado en la percepción, motivación, conocimiento, experimentación y valoración, ya revisados tradicionalmente en los estudios del turismo (McCannel 1976; Duncan 1878, Embacher y Buttle 1989; Urry 1990, entre otros). En realidad, se trata de introducirse en la imagen percibida del paisaje con los atractivos que ha logrado aglutinar, las fuentes previas de la información, la determinación del grado de interés, la importancia concedida a las vistas, su valoración, la influencia en la elección del destino, y las razones en la recomendación de las vistas.

Es fundamental conocer las imágenes percibidas de los paisajes que han conseguido elaborar los turistas, y que engloban una serie de ideas, ideologías, valores, imágenes preconcebidas y, en suma, unos conocimientos a través de las percepciones individuales que han construido individualmente. Estudios aproximativos de imágenes percibidas se han llevado a cabo por varios analistas españoles (Galí y Donaire, 2006; Anato Martínez, Rivas y González, 2010).

En la segunda realidad concreta se buscó la opinión de 35 especialistas a través de un Panel de Experto sobre el paisaje de Toledo como recurso turístico en sí mismo. Participaron 19 especialistas de distintas instituciones y 16 especialistas de empresas privadas. Los expertos del Panel se dividen en dos grupos, el grupo de empresarios, formado por actores económicos y políticos del turismo tales como hoteles, hosteleros, agencias de viajes, tour operadores y otros negocios relacionados directamente con el turismo en la ciudad de Toledo. El segundo grupo comprende agentes sociales vinculados al mundo del patrimonio y la cultura como ejemplo, la real Fundación Toledo, la Real Academia de Ciencias Históricas y Bellas Artes o el Consorcio de Toledo.

Las preguntas del Panel se dividen en cuatro rasgos básicos: 1. Imagen de destino de Toledo. 2. Paisaje como producto turístico. 3. Gestión del paisaje como producto turístico y 4. Promoción y difusión del paisaje como oferta comerciable.

\section{Análisis y resultados}

\subsection{La percepción y valoración de los paisajes culturales e imágenes de destino a una muestra de turistas}

Para el análisis de la percepción y valoración de los paisajes culturales e imágenes de destino, se trata de reconstruir el mapa conceptual previo que tienen los turistas, la percepción y valoración de las imágenes de destino, las emociones y experiencias que tienen en las visitas de ciudades históricas y emblemáticas, y las conductas, toma de decisiones, revisita o fidelización y recomendaciones de la misma. 


\subsubsection{El componente cognitivo o perceptual}

Para conocer los conocimientos previos de los paisajes culturales como imágenes de destino que tienen los turistas, se les preguntó si antes de realizar la visita de este destino seleccionado tenían conocimientos de los diferentes valores paisajísticos. En la Tabla 1 se advierte que el turista, en general, conoce de antemano componentes importantes de los paisajes culturales tales como las panorámicas o vistas urbanas del destino $(73,1 \%) \mathrm{y}$, sobre todo, los escenarios interiores del destino $(78,1 \%)$ como plazas y calles. Sin embargo, solo un 35\% consigue vincular el destino con imágenes de cuadros u obras literarias. En consecuencia, los escenarios interiores del destino como plazas y calles, las panorámicas o vistas urbanas del destino y los parajes naturales son los que han sido captados en las tres cuartas partes de la población. De manera pormenorizada se les preguntaba cómo han conocido la existencia del paisaje cultural como imagen de destino al que han viajado, y los medios se distribuyen en este orden:

"Por lecturas sobre el lugar; por otros familiares y amigos; porque me lo sugirieron amigos; por haber visto algún cuadro, película o programa de TV relacionado con el lugar; por la propaganda turística a través de Internet; por información en la prensa; y por relaciones familiares con el lugar".

Después de haber visitado las localidades se les preguntó qué es lo que más han percibido y valorado de las vistas panorámicas y del lugar, y se obtuvo según las medias (sobre Moda=5) que las imágenes mejor puntuadas son las que hacen referencia a las vistas del conjunto histórico desde lo alto de una torre o de cualquier otro edifico $(4,23)$, seguidas de las vistas de algún o algunos espacios interiores: plazas, calles, cruce de calles $(4,18)$, y en tercer lugar las vistas del conjunto desde fuera del mismo, desde algún lugar o lugares donde existan buenas panorámicas $(4,11)$. En general, las vistas panorámicas que engloban la totalidad histórica y su entorno es lo que más se prioriza, especialmente porque contiene el conjunto histórico y todos sus elementos (imagen idealizada que se lleva el turista). Después se incorporan esas vistas desde espacios donde pueda haber relación e interacción social entre las gentes de las plazas, calles y cruce de calles, y en un tercer lugar vuelve a primar las vistas del conjunto desde fuera, en las que se permite una percepción visual subjetiva y más individualizada. La conjunción entre la contemplación del paisaje cultural como imagen de destino en un todo con las conductas turísticas van imbricadas, y son idóneas en el espacio cultural y urbano que prevalecen ante las vistas del conjunto desde fuera del mismo. Por último, se les pidió que valorasen las imágenes de destino panorámicas de la localidad visitada en su conjunto, y en la misma Tabla 1, se aprecia una valoración positiva de las vistas urbanas.

\section{Tabla 1: Conocimiento previo y percepción/valoración de los paisajes culturales como imágenes de destino}

\begin{tabular}{|l|c|c|}
\hline Conocimiento previo antes de realizar la visita & $\%$ & Frecuencia \\
\hline Panorámicas o vistas urbanas del destino & $73,1 \%$ & 366 \\
\hline Escenarios interiores del destino (plazas, calles...) & $78,1 \%$ & 390 \\
\hline Parajes naturales & $57,5 \%$ & 287 \\
\hline Alguna vista por algún cuadro famoso o descripción literaria & $35,2 \%$ & 176 \\
\hline Lo que más se percibe y valora & $\bar{X}$ & Mo \\
\hline $\begin{array}{l}\text { Vistas del conjunto desde fuera del mismo, desde algún lugar o lugares } \\
\text { donde existan buenas panorámicas }\end{array}$ & 4,11 & 5 \\
\hline $\begin{array}{l}\text { Vistas del conjunto histórico desde lo alto de una torre o de cualquier otro } \\
\text { edificio }\end{array}$ & 4,23 & 5 \\
\hline Vistas de algún o algunos espacios interiores: plazas, calles, cruce de calles & 4,18 & 5 \\
\hline Valoración de las vistas panorámicas de la localidad & $\overline{\boldsymbol{X}}$ & Mo \\
\hline Imágenes de destino de vistas urbanas de la localidad en su conjunto. & 4,22 & 5 \\
\hline
\end{tabular}

Fuente: elaboración propia. 


\subsubsection{El componente afectivo o emotividad}

El componente afectivo o emotividad se experimenta en el lugar visitado, que son ciudades monumentales o lugares históricos, que dan cuenta de la satisfacción global que se obtiene de las prácticas turísticas. En la Figura 1 se aprecia que, en general, las prácticas del turista están bastante delimitadas por la contemplación del paisaje cultural y la satisfacción que experimenta en la visita y duración de la misma, en la que las visitas y las vistas de las ciudades históricas y sus paisajes culturales son las que acaparan las posibilidades que se ofertan, para después aglutinar las prácticas relacionadas con visita de monumentos, ambiente de calles y plazas, trato con las gentes, disfrutar de familiares, la gastronomía, disfrute de paisajes de naturaleza, museos, fiestas populares, espectáculos y zona comercial.

\section{Figura 1: Satisfacción con las actividades, rutas y manifestaciones de ocio y recreación que facilitan las ciudades monumentales}

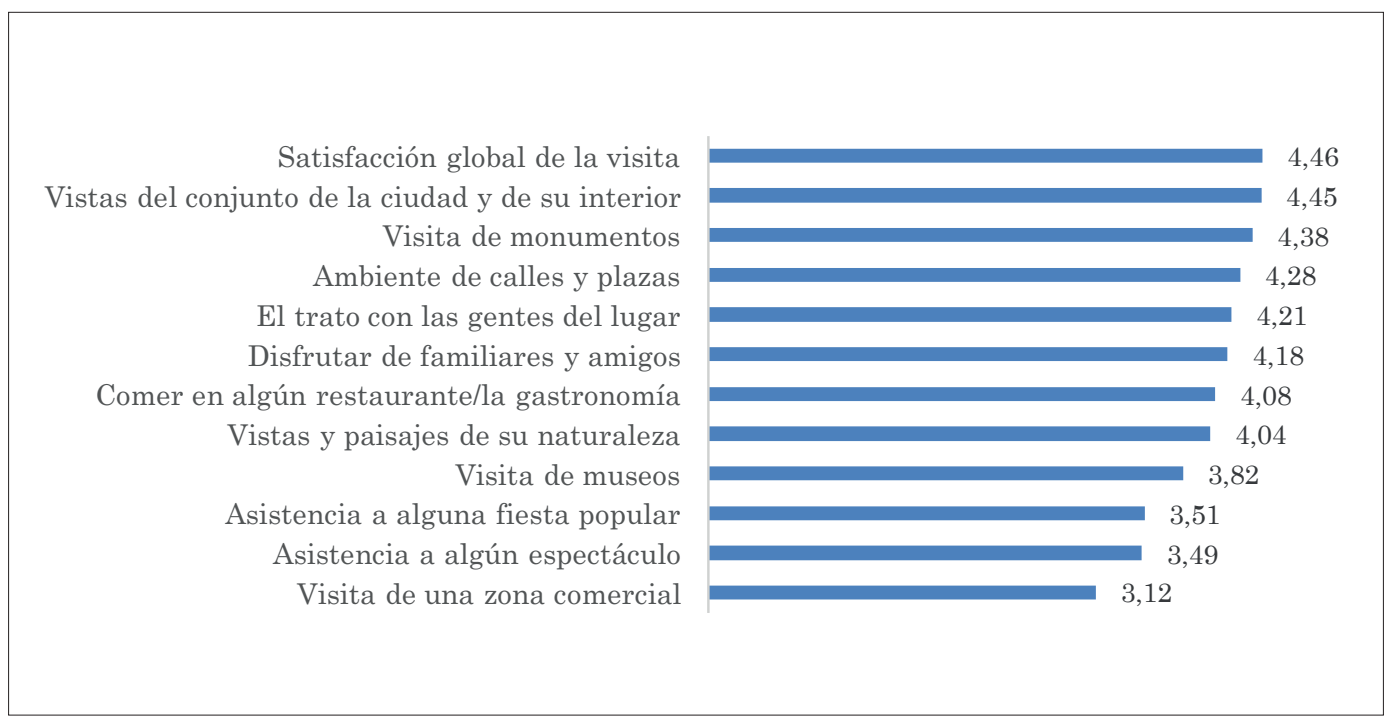

Fuente: elaboración propia.

Los elementos de calidad de los paisajes culturales reúnen, en general, buenas condiciones y equipamientos de manera que estén bien aprovechados para las vistas panorámicas y los entornos naturales de las ciudades históricas que han visitado. Según las medias obtenidas en las respuestas, son muy bien valorados los lugares y entornos al estar limpios $(4,13)$ y con buena presencia, al igual que la información turística de la localidad $(4,12)$ que dispone de indicaciones básicas para las vistas y panorámicas que se requieren en las visitas de los turistas y visitantes que acuden al lugar.

Otros aspectos relevantes son la infraestructura que ofrecen estas ciudades históricas visitadas respecto a los espacios habilitados que hay para poder disfrutar de las vistas $(4,09)$ que más atraen, las señalizaciones $(3,99)$ que dirigen las rutas de los espacios urbanos y naturales, la conservación e inexistencia de elementos visuales que los perturben $(3,96)$, y las facilidades que existen para el acceso y aparcamiento a los mismos $(3,32)$. Estas medias obtenidas a través del componente afectivo y emocional, señalan que podrían mejorarse los accesos y aparcamientos, la conservación y elementos visuales que perturban las vistas panorámicas, señalizar mejor las rutas de los espacios urbanos y naturales y, habilitar más espacios o lugares desde donde poder tener esas vistas.

La siguiente cuestión, sondear cuáles son las ciudades históricas españolas que más han impactado al visitante a través de emociones y experiencias en los últimos viajes realizados. Para la mayoría, la ciudad monumental que más ha impactado ha sido Granada, seguida de Toledo, y es una tendencia que se repite en la segunda opción, pero intercambiada, por lo que son las dos ciudades que más connotaciones tienen para el turista cultural. Y en quinto lugar aparece Córdoba. 
Tabla 2: Ciudades históricas españolas que más han impactado por sus paisajes culturales

\begin{tabular}{|l|c|c|}
\hline \multicolumn{3}{|c|}{ Primera opción } \\
\hline & Frec. & $\%$ \\
\hline Granada & 72 & $14,4 \%$ \\
\hline Toledo & 49 & $9,8 \%$ \\
\hline Barcelona & 41 & $8,2 \%$ \\
\hline Madrid & 38 & $7,6 \%$ \\
\hline Córdoba & 19 & $3,8 \%$ \\
\hline Total & $\mathbf{2 1 9}$ & $\mathbf{4 3 , 7} \%$ \\
\hline \multicolumn{3}{|c|}{$\bar{X}$} \\
\hline \multicolumn{3}{|c|}{4,53} \\
\hline
\end{tabular}

\begin{tabular}{|l|c|c|}
\hline \multicolumn{3}{|c|}{ Segunda opción } \\
\hline & Frec. & $\%$ \\
\hline Toledo & 54 & $10,8 \%$ \\
\hline Granada & 46 & $9,3 \%$ \\
\hline Barcelona & 38 & $7,5 \%$ \\
\hline Madrid & 32 & $6,45 \%$ \\
\hline Córdoba & 21 & $4,2 \%$ \\
\hline Total & $\mathbf{1 9 1}$ & $\mathbf{3 8 , 3} \%$ \\
\hline \multicolumn{3}{|c|}{$\bar{X}$} \\
\hline \multicolumn{3}{|c|}{4,39} \\
\hline
\end{tabular}

\begin{tabular}{|l|c|c|}
\hline \multicolumn{3}{|c|}{ Tercera opción } \\
\hline & Frec. & $\%$ \\
\hline Madrid & 36 & $7,2 \%$ \\
\hline Córdoba & 30 & $6 \%$ \\
\hline Barcelona & 27 & $5,3 \%$ \\
\hline Granada & 25 & $5,0 \%$ \\
\hline Toledo & 20 & $4,1 \%$ \\
\hline Total & $\mathbf{1 3 8}$ & $\mathbf{2 7 , 6} \%$ \\
\hline \multicolumn{3}{|c|}{$\overline{\mid}$} \\
\hline \multicolumn{3}{|c|}{4,35} \\
\hline
\end{tabular}

Fuente: elaboración propia.

En dichas ciudades se vislumbran dos categorías, la primera contiene la esencia más pura de ciudad histórica, con diversidad cultural, de tamaño pequeño y con entornos y paisajes naturales. Y la segunda hace referencia a ciudades metropolitanas, también históricas, que han desarrollado un ocio moderno, y con entornos y paisajes naturales variados (Véase Tabla 2).

Desde una perspectiva más concreta se intenta que el turista especifique las localidades destacadas en las ciudades preferentes (paisajes culturales como imágenes de destino), y que le hayan parecido especialmente dignos de ser visitados. (Véase Tabla 3). Se obtiene que las vistas panorámicas de Granada son las más señaladas por los turistas de nuestra muestra en las dos primeras vistas de la opción primera (A la Alhambra, Desde Alhambra), al igual que en las dos primeras vistas y la cuarta de la opción segunda (Vistas a la Alhambra, desde la Alhambra, Desde el Albaicín de Granada) y en la primera vista (A la Alhambra) de la opción tercera. En realidad, la ciudad monumental y el entorno se ensamblan aquí de manera única y está contenida en un todo armónico e inseparable, que la hace impactante e interesante en su conjunto.

Sin embargo, Toledo que es la segunda ciudad histórica señalada como preferente no aparece aquí indicada, a pesar de las extraordinarias panorámicas que posee y el entorno natural que la rodea. Sus vistas panorámicas resultan casi desconocidas por la muestra de turistas pese a que tiene los recursos naturales idóneos, si bien es reconocida por la imagen del Greco, lo que indica que no tienen imagen para recordar de imágenes de destino para ser disfrutadas por rutas de manera directa, curiosamente, en las pinturas del Greco aparecen muy marcadas las vistas panorámicas.

Tabla 3: Paisajes culturales como imágenes de destino más interesantes según los turistas

\begin{tabular}{|l|c|c|}
\hline \multicolumn{3}{|c|}{ Primera opción } \\
\hline Vistas... & Frec. & $\%$ \\
\hline A la Alhambra & 34 & $6,9 \%$ \\
\hline Desde Alhambra & 17 & $3,4 \%$ \\
\hline $\begin{array}{l}\text { Desde el Albaicín } \\
\text { de Granada }\end{array}$ & 16 & $3,1 \%$ \\
\hline $\begin{array}{l}\text { Desde Montjuic } \\
\text { A la Plaza Mayor } \\
\text { de Salamanca }\end{array}$ & 11 & $2,5 \%$ \\
\hline $\begin{array}{l}\text { Al parque Güell } \\
\text { Vistas a la }\end{array}$ & 10 & $2,1 \%$ \\
\hline Sagrada Familia & 8 & $1,6 \%$ \\
\hline
\end{tabular}

\begin{tabular}{|l|c|c|}
\hline \multicolumn{3}{|c|}{ Segunda opción } \\
\hline Vistas... & Frec. & $\%$ \\
\hline Vistas a la Alhambra & 22 & $4,3 \%$ \\
\hline Desde la Alhambra & 14 & $2,8 \%$ \\
\hline Desde Montjuic & 11 & $2,1 \%$ \\
\hline $\begin{array}{l}\text { Desde el Albaicín } \\
\text { de Granada }\end{array}$ & 10 & $1,9 \%$ \\
\hline $\begin{array}{l}\text { Desde la Giralda } \\
\text { de Sevilla }\end{array}$ & 10 & $2,1 \%$ \\
\hline $\begin{array}{l}\text { Al casco histórico } \\
\text { de Cáceres }\end{array}$ & 10 & $2 \%$ \\
\hline $\begin{array}{l}\text { Vistas a la Giralda } \\
\text { de Sevilla }\end{array}$ & 8 & $1,5 \%$ \\
\hline $\begin{array}{l}\text { A la Plaza de } \\
\text { Obradoiro de } \\
\text { Santiago }\end{array}$ & 8 & $1,6 \%$ \\
\hline
\end{tabular}

\begin{tabular}{|l|c|c|}
\hline \multicolumn{3}{|c|}{ Tercera opción } \\
\hline Vistas... & Frec. & $\%$ \\
\hline A la Alhambra & 14 & $2,9 \%$ \\
\hline $\begin{array}{l}\text { A la Mezquita } \\
\text { de Córdoba }\end{array}$ & 14 & $2,7 \%$ \\
\hline $\begin{array}{l}\text { A la Plaza Mayor } \\
\text { de Salamanca }\end{array}$ & 11 & $2,2 \%$ \\
\hline $\begin{array}{l}\text { Desde el río o el } \\
\text { puente de Córdoba }\end{array}$ & 10 & $1,9 \%$ \\
\hline $\begin{array}{l}\text { A la playa de } \\
\text { la Concha (San } \\
\text { Sebastián) }\end{array}$ & 9 & $1,8 \%$ \\
\hline $\begin{array}{l}\text { Al acueducto } \\
\text { de Segovia }\end{array}$ & 9 & $1,7 \%$ \\
\hline $\begin{array}{l}\text { A la catedral } \\
\text { de Sevilla }\end{array}$ & 8 & $1,5 \%$ \\
\hline $\begin{array}{l}\text { Desde la Catedral } \\
\text { de Santiago }\end{array}$ & 8 & $1,5 \%$ \\
\hline
\end{tabular}


Barcelona se sitúa la segunda en vistas panorámicas (Desde Montjuic, Vistas a la Sagrada Familia, $\mathrm{Al}$ parque Güell) en la primera y segunda opción, Salamanca la tercera en primera y tercera opción con su vista A la Plaza Mayor de Salamanca, y Córdoba sólo se señala en la tercera opción en el segundo y cuarto puesto (A la Mezquita de Córdoba, Desde el río o el puente de Córdoba). No menos importantes son Sevilla que figura en las opciones segunda (Desde la Giralda de Sevilla y vistas a la Giralda de Sevilla) y tercera (A la catedral de Sevilla), y Santiago de Compostela también en las opciones segunda (A la Plaza de Obradoiro de Santiago) y tercera (Desde la catedral de Santiago). Por último, las ciudades de Cáceres en segunda opción (el casco histórico de Cáceres) y en tercera opción, San Sebastián (A la Playa de la Concha) y Segovia (el acueducto de Segovia). Todas ellas son muestra de la diversidad que tiene España en su riqueza cultural y paisajística que delimita los perfiles de un turismo cultural repleto de historia en magníficos entornos naturales para su preservación y sostenibilidad.

\subsubsection{El componente conativo o de conducta}

Como consecuencia de los dos componentes anteriores (cognitivo o perceptual y afectivo o emocional) el componente conativo indaga sobre si los turistas volverían a visitar esa ciudad y si recomendarían la visita, y la respuesta es muy positiva, con una media de 4,26 y 4,58 respectivamente, con una moda de 5. Es decir, más de tres cuartas partes (83\%) sí recomendarían el lugar y considerarían las vistas como destino cultural.

Considerando el sexo, la edad y el nivel de estudios, las vistas (imágenes de destino) se tienen en cuenta en relación a los datos de la Figura 2. Aquí se observa que los hombres consideran las vistas panorámicas como elemento de recomendación del lugar en una proporción ligeramente mayor que las mujeres, y especialmente el grupo de 22 a 44 años con estudios universitarios y estudios secundarios. Este hecho también tiene su razón de ser por ser este grupo el que más viaja de todos y el que más experiencia dispone para pronunciarse en este sentido.

Figura 2: Consideración de las vistas panorámicas como elemento de recomendación del lugar en función del sexo, edad y nivel de estudios

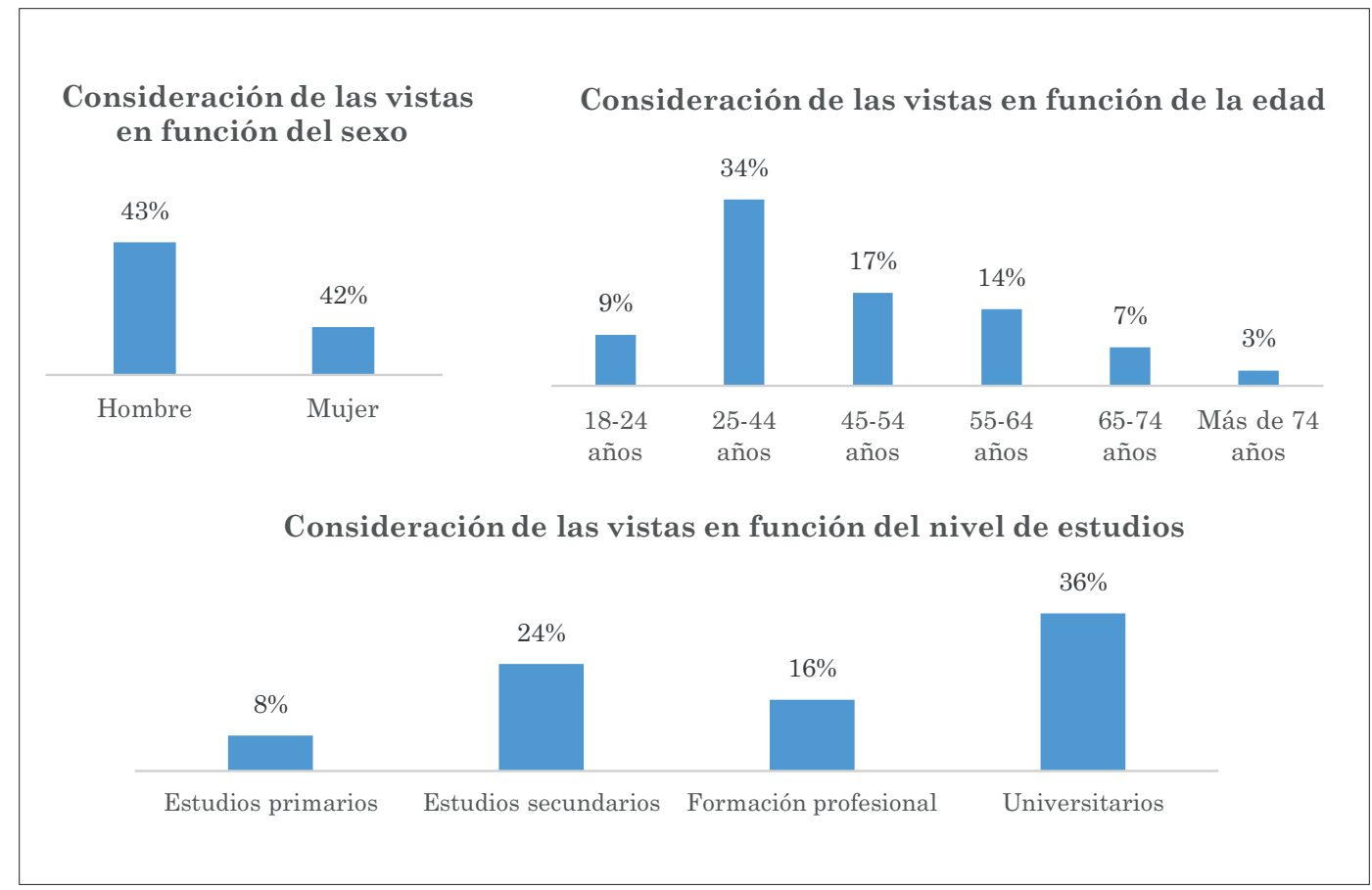

Fuente: elaboración propia. 
Finalmente, nuestra investigación concluye con la búsqueda de las conductas del turista en el momento de la visita donde se le pregunta en qué medida le interesaría hacer recorridos comentados, visitar panorámicas de la ciudad o visitar monumentos. En la Tabla 4 se aprecia, según las medias, que están muy bien puntuadas las visitas a puntos panorámicos de la ciudad $(4,29)$, y visitar monumentos y ver museos $(4,20)$, y en un tercer orden de importancia se sitúa realizar recorridos comentados por las diversas vistas de la localidad, desde su exterior y desde su interior $(4,01)$.

Primero se quiere conocer y disfrutar la totalidad del lugar a través de las panorámicas más generales, para pasar después a lugares y actividades más concretas como visitar monumentos y ver museos, y para el final de la visita realizar recorridos comentados. Si desagregamos por sexo, edad y nivel de estudios, son las mujeres las que puntúan más alto las visitas panorámicas de la ciudad, las de monumentos y museos y los recorridos comentados por las diversas vistas, en tanto que los hombres puntúan en una menor proporción especialmente esta última opción.

Tabla 4: Conductas del turista en el momento de la visita

\begin{tabular}{|l|c|c|}
\hline En qué medida le interesaría... & $\overline{\boldsymbol{X}}$ & Mo \\
\hline $\begin{array}{l}\text { Realizar recorridos comentados por las diversas vistas de la localidad, } \\
\text { desde su exterior y desde su interior }\end{array}$ & 4,01 & 5 \\
\hline Visitar puntos panorámicos de la ciudad & 4,29 & 5 \\
\hline Visitar monumentos y ver museos & 4,20 & 5 \\
\hline
\end{tabular}

Fuente: elaboración propia.

En relación a la edad el grupo de más edad es el que más destaca en interés por estas tres opciones, y en el otro extremo, los más jóvenes son los que menor interés manifiestan. Asimismo, por el nivel de estudios se inclinan en mayor proporción a disfrutar de las vistas los que tienen Formación profesional y los de Estudios Secundarios.

\subsection{Panel de Experto sobre los componentes de la imagen de destino de los paisajes culturales de Toledo, estrategias de desarrollo y promoción}

En la percepción y valoración de los paisajes culturales e imágenes de destino se ha obtenido que la proyección de la imagen de las ciudades históricas preferentes son las que perduran en el imaginario del turista, si bien Toledo no tiene una imagen lo suficientemente consolidad en su proyección, pese a disponer de extraordinarias panorámicas y el entorno natural que la rodea. De aquí que el Panel de Experto (19 expertos de instituciones y 16 expertos de empresas privadas) trate de investigar los componentes de la imagen de destino de los paisajes de Toledo, las estrategias de desarrollo y su promoción (Véase Tabla 5).

\subsubsection{Imagen de destino de Toledo}

La imagen turística de Toledo es el primer elemento que se investiga en el Panel del Experto (Rodríguez, 2015), donde se pide que valoren determinadas características propias que conforman su imagen de marca. Sin duda, las medias obtenidas en la opinión de los expertos indican que el atributo más valorado es el de la consideración de Toledo como Ciudad Patrimonio de la Humanidad (4,16), y ya con cierta distancia se consideran importantes los paisajes culturales $(3,91)$ y la ciudad del Greco $(3,81)$. El atributo menos valorado es la imagen de Toledo como ciudad imperial $(3,61)$.

Se observa que las instituciones valoran con una mayor puntuación que los de empresas privadas todos los atributos de la ciudad, y que la mayor diferencia de valoración es la de la imagen de Toledo como ciudad de las tres culturas, como ciudad imperial, medieval y barroco. Los elementos de atracción de la imagen que todos los expertos aportan, además de los ofrecidos, son los siguientes:

"Los monumentos y museos, sus campos y pueblos, rutas por las ciudades teresianas, la red de ruta de Carlos V, Toledo musulmán, Toledo leyenda, Toledo romano, medieval y barroco, el hospital de Talavera, las sinagogas y mezquitas, museo de Santa Cruz, los conventos, la vista panorámica del Parador, el entramado urbano de la ciudad y el carnaval". 


\section{Tabla 5: Valoración de expertos sobre los paisajes culturales e imágenes de destino de Toledo como recursos turísticos sostenibles}

1. IMAGEN DE DESTINO DE TOLEDO

- Ciudad Patrimonio de la Humanidad $(4,16)$.

- Paisajes culturales $(3,91)$.

- Ciudad del Greco $(3,81)$.

2. PAISAJE COMO PRODUCTO TURÍSTICO

- Interpretación de los paisajes de Toledo para comprender mejor la historia y los problemas de la ciudad actual $(4,58)$.

- La puesta en valor de los paisajes toledanos por el turismo, para su conservación $(4,42)$.

- Los paisajes culturales podrían ser un producto turístico en sí mismo $(4,21)$.

3. GESTIÓN DEL PAISAJE COMO PRODUCTO TURÍSTICO

- Los paisajes de la ciudad pueden ser ofertados como producto turístico diferenciado convenientemente interpretados y presentados (folletos, web, publicidad) $(3,95)$.

- Promocionar rutas de senderismo, paseos por las riberas del Tajo, visitas nocturnas $(4,38)$.

- La puesta en valor de los paisajes ayudaría a conservar paisajes heredados del pasado hoy amenazados $(4,23)$.

4. PROMOCIÓN Y DIFUSIÓN DEL PAISAJE COMO OFERTA COMERCIABLE

- Internet y las Redes Sociales $(4,55)$.

- El papel actual de Internet en la promoción del paisaje no es adecuada $(2,62)$.

- Aumentar la presencia en Internet y en las redes Sociales $(4,61)$.

Fuente: "Opinión del Experto sobre el paisaje de Toledo como recurso turístico en sí mismo", elaboración técnica de Ainhoa Rodríguez Oromendia en "Dinámicas comparadas para una gestión sostenible de los paisajes cultuales a través del turismo" (CULTURPAIS), Ref. CSO2011-24966, Ministerio de Ciencia e Innovación. Investigador principal: M. Antonio Zárate Martín.

En general, los elementos de atracción turística de Toledo vienen muy delimitados por la Catedral que destaca por encima de los demás $(4,82)$, seguidos de otros elementos que también son valorados positivamente como los paisajes y vistas de Toledo $(4,24)$, el Alcázar $(4,18)$ y el Museo del Greco $(4,15)$. Otros elementos de atracción son la Fiesta del Corpus $(4,71)$, la obra del Greco $(4,43)$ y los monumentos de la ciudad $(4,20)$, y los que menos relevancia tienen son la gastronomía $(3,37)$ y los congresos $(3,03)$.

De cara a la construcción de la imagen turística los expertos consideran importantes la adecuada promoción de la ciudad a través de propaganda institucional y empresarial por medio de Internet $(3,85)$, las representaciones de los artistas $(3,47)$ y las descripciones literarias de la ciudad y de sus paisajes $(3,39)$. El cine y las películas rodadas en Toledo $(3,06)$ son los elementos menos valorados como constructor de imagen turística. Y las representaciones plásticas más valoradas para dar a conocer la imagen de Toledo en el mundo son la vista del Toledo del Greco del Metropolitan Museum de Nueva York $(4,33)$, y la vista de Toledo del Museo del Greco de Toledo $(4,27)$.

El recuerdo que les queda a los expertos de la imagen turística de Toledo hace referencia a las vistas del conjunto de la ciudad desde El Valle, la vista panorámica de la ciudad y las calles del casco antiguo, el Alcázar y la Catedral, la belleza de Toledo en su conjunto, su estructura urbana, las puertas del río Tajo circundando la ciudad, la vista del Alcázar desde la carretera y la vista de los Cigarrales.

\subsubsection{Paisaje como producto turístico}

Según las medias obtenidas se da especial importancia a la opción de dar a conocer la interpretación de los paisajes de Toledo con el fin de comprender mejor la historia de la ciudad y los problemas actuales de Toledo $(4,58)$, y se valora la puesta en valor de los paisajes toledanos por el turismo para su conservación y transmisión a futuras generaciones. Y es un hecho la realidad de que los paisajes de Toledo no son lo suficientemente conocidos y valorados por los turistas y visitantes $(2,84)$, y se estima muy favorablemente su conversión en productos turísticos en sí mismos. Todos los expertos en su conjunto han sugerido de manera complementaria aplicar una política de limpieza del rio Tajo, y están de acuerdo en fomentar la conservación del paisaje y preservarlo del impacto urbanístico.

La elección de hotel para los visitantes es de suma relevancia, ya que la ubicación de los hoteles en el casco antiguo facilita el acceso y el aparcamiento $(3,52)$, y no lo son tanto las estrellas del hotel 
$(2,52)$, o las vistas del conjunto histórico $(2,62)$. Los expertos opinan que los turistas valoran bastante poco la categoría del hotel $(2,13)$ cuando hay que elegir alojamiento en la ciudad de Toledo. Existen otros factores que también señalan como rasgos importantes para la selección del hotel tales como el precio, la existencia de aparcamiento público en el casco, y la confianza de los turistas en la agencias y tour operadores.

Según el criterio de las empresas y las instituciones los elementos más valorados para celebrar congresos y eventos familiares (bodas) son los valores monumentales $(4,35)$ y paisajísticos $(4,21)$ de la ciudad de Toledo. Y en relación a los paisajes que son considerados más atractivos por los turistas se destacan las plazas y calles del interior del casco histórico $(4,60)$, las vistas de Toledo desde el Parador $(4,50)$, y la vista del conjunto de la ciudad desde los Cigarrales $(4,17)$. En tanto que los menos valorados son las vistas de la Vega Alta y Huerta del Rey $(2,06)$, y las vistas de la Vega Baja desde la Diputación $(2,26)$. Los expertos sugieren otras vistas como las del puente de San Martín, el monasterio de San Juan de los Reyes y el paseo por el río desde la fábrica de Armas.

\subsubsection{Gestión del paisaje como producto turístico}

Empresas e instituciones muestran a través de sus opiniones en el Panel del Experto que los paisajes de Toledo no están suficientemente promocionados desde la perspectiva turística. Insisten más las instituciones en la escasa información que se proyecta de los paisajes culturales de Toledo en las páginas webs institucionales y en los promotores turísticos. Como opciones se señalan las de añadir recorridos interiores de la ciudad en el paisaje urbano y unir naturaleza e historia.

Los expertos de las empresas estiman con una valoración de 4,22 (superior a la de las instituciones con 3,77 ) que los paisajes de la ciudad pueden ser ofertados como producto turístico diferenciado siempre que sean convenientemente interpretados y presentados al gran público a través de folletos turísticos, páginas webs y campañas publicitarias (3,95 empresas e instituciones). Ahora bien, los expertos de las empresas y los de las instituciones no están de acuerdo con la afirmación de que los paisajes solo interesan como escenario para la ubicación de hoteles y la celebración de fiestas familiares, ni sopesan que los paisajes de Toledo solo puedan atraer a personas muy interesadas por la historia y la cultura, pero no al gran público. En las preguntas abiertas los principales aspectos de la oferta actual del turismo toledanos estiman lo siguiente:

- "Los monumentos constituyen el aspecto turístico más relevante de la ciudad".

- "La belleza de la ciudad de Toledo".

- "Las plazas, las calles, las fiestas y tradiciones. Su cultura y gastronomía".

Respecto a las estrategias para poner en valor el paisaje cultural como producto turístico, el Panel de Experto aporta las propuestas expresadas en grado de acuerdo con las respuestas (1= muy en desacuerdo; $5=$ muy de acuerdo) que figuran a continuación:

- "Promocionar rutas de senderismo, paseos por las riveras del Tajo, visitas nocturnas $(4,38)$ ".

- "Desarrollar programas educativos que hagan posible difundir los valores culturales de los paisajes toledanos $(4,14)$ ".

- "Relacionar los paisajes observables sobre el terreno con las descripciones literarias y representaciones $(4,23)$ ".

- "Preparar rutas guiadas para observar, comentar y explicar cada uno de los paisajes culturales de Toledo $(4,09)$ ".

- "Aprovechar las vías existentes a lo largo del río y definir puntos estratégicos con paneles explicativos (4,09)".

En cuanto a los efectos que podría tener la puesta en valor de los paisajes de Toledo sobre la actividad turística de la ciudad, el Panel de Experto aporta los efectos expresados en grado de acuerdo con las respuestas (1= muy en desacuerdo; $5=$ muy de acuerdo) que figuran a continuación:

- "Ayudaría a conservar paisajes heredados del pasado y que hoy se encuentran amenazados por la presión urbanística y la presión inmobiliaria $(4,23)$ ".

- "Facilitaría conocer la relación entre las imágenes visuales de la ciudad actual y las imágenes plásticas transmitidas a lo largo de la historia por los artistas $(4,13)$ ".

- "Ayudaría a mejorar la imagen turística de la ciudad $(4,14)$ ".

- "Sería un elemento más de atracción turística, que podría hacer aumentar el número de días de permanencia en la ciudad $(4,19)$ ”.

- "Sería indiferente respecto al comportamiento actual de la demanda turística $(2,38)$ ". 
El Panel de Experto estima que para la promoción de los paisajes culturales de Toledo es importante contar con la colaboración de la Real Academia de Bellas Artes y Ciencias Históricas de Toledo (4,06), así como la colaboración del Consorcio de la ciudad de Toledo $(3,94)$, en cambio la opción menos valorada se refiere a la responsabilidad exclusiva del Patronato Municipal de Turismo (2,76). En sus aportaciones, los expertos señalan que deberían colaborar todas las administraciones, y la implicación del Ayuntamiento y la Comunidad Autónoma.

\subsubsection{Promoción y difusión del paisaje como oferta comerciable}

Los tres elementos de promoción y difusión de los paisajes culturales, se encuentran en los medios de comunicación, el papel actual de Internet en la promoción del paisaje, y las redes sociales. Los expertos valoran que todos los medios de promoción son adecuados, aunque los más valorados son Internet y las redes sociales $(4,55)$, seguidas de las agencias de viaje $(4,36)$ y los tour-operadores $(4,28)$. Los que menos se consideran como comerciales son los libros y folletos $(4,03)$ y las revistas y periódicos $(4,10)$, sin menoscabar el sistema boca-oreja que puede seguir siendo un medio de promoción bastante útil.

Sin duda, tanto en el estudio de la percepción y valoración de los paisajes culturales e imágenes de destino a una muestra de turistas, como en el Panel del Experto, la imagen de los paisajes culturales que en Internet se proyectan no es adecuada ni suficiente en el caso de los expertos $(2,62)$, y es una preocupación que más han mostrado los expertos de las instituciones. Tanto las empresas como las instituciones han manifestado que es muy positivo para el desarrollo de los paisajes culturales aumentar su presencia en Internet y las redes sociales, así como promocionar imágenes diferentes de Toledo, y evitar el poner una única vista.

\section{Conclusiones}

Los paisajes culturales como imágenes de destino ofrecen un potencial para el sector turístico importante en la actualidad. Se trata de imágenes de destino únicos que se ofrecen para ser consumidos creativamente con el trasfondo histórico, cultural y natural al que pertenecen. Su puesta en valor como producto turístico comporta desarrollo económico y social para la zona, y la preservación y mantenimiento del patrimonio. La proyección de la imagen de destino forma parte de un proceso en el que intervienen los componentes cognitivos o perceptivos, los efectivos o emocionales y los conativos o de conducta. La polaridad positiva de la percepción, o en su caso, la polaridad negativa, es un predictor de la revisita o fidelización del turista, que va a reincidir en la vuelta al lugar en el que se ha experimentado satisfacción y agrado.

La defensa de los paisajes como valores patrimoniales se consolida a finales de la década de los ochenta (Carta de Toledo-Washington), para asentarse al final del siglo XX y principios del XXI con la conservación del paisaje en el urbanismo y la ordenación del territorio. Seguidamente, el Convenio Europeo del Paisaje (2008) y las orientaciones de la Unesco (2012) culminan la puesta en valor de los paisajes culturales en el ámbito del turismo.

Los paisajes culturales son patrimonios en entornos naturales y culturales, y en ellos tienen lugar los paisajes, sitios históricos, emplazamiento, entornos construidos, biodiversidad, tradiciones pasadas y presentes y, en suma, conocimientos y experiencia vital. El paisaje cultural es un territorio, y la manera en que es percibido por la población, y es fruto del resultado de la acción y de la interacción de los factores naturales y humanos que ahí han intervenido. Tiene una identidad única y una dinámica evolutiva a través del tiempo.

Determinados por el mundo digital en la actualidad, los paisajes culturales son, ante todo, imágenes de destino que deben proyectarse adecuadamente para el conocimiento y percepción que se obtenga de ellos, en las páginas webs de Internet y en las redes sociales principalmente. Más en concreto, se estima que la imagen es fundamental, ya que tiene un impacto positivo en el valor percibido, la calidad, la satisfacción y la intención de conducta. En esta percepción de la imagen, la satisfacción que se obtiene de los atributos de la imagen de destino tiene una influencia positiva en la intención de volver a visitar el lugar, y recomendar el destino.

Los resultados del estudio muestran que el componente cognitivo o perceptual que tiene el turista es un predictor de la revisita, y aquí tiene que ver la imagen proyectada adecuada o no del lugar visitado. De manera que la percepción de la muestra del estudio da cuenta de un conocimiento que se tiene previo antes de efectuar la visita, más concretamente, los escenarios interiores de destino, y las panorámicas o vistas urbanas del lugar. 
Las imágenes mejor puntuadas son las que hacen referencia a las vistas del conjunto histórico desde lo alto de una torre o desde cualquier otro edificio, seguidos de espacios interiores (plazas, calles, cruce de calles). Lo que más se prioriza son las vistas panorámicas del conjunto histórico y todos sus elementos. A partir de aquí, de esta percepción conocida y percibida positivamente, el componente afectivo o emotividad se experimenta con el disfrute de los elementos de la imagen de desino, tales como visitas, rutas, museos, ambiente de calles y plazas, gastronomía, fiestas populares, etc.

En este sentido, el caso de las ciudades históricas que más han impactado demuestra la importancia de la imagen proyectada de los paisajes culturales. Se sitúan en primera fila Granada y Toledo, seguidas de Barcelona y Madrid, y a continuación Córdoba. Ahora bien, Toledo que es la segunda ciudad histórica señalada como preferente, no figura en la relación de paisajes culturales como imágenes de destino más interesantes por los turistas (Tabla 3.) Sus vistas panorámicas resultan casi desconocidas por la muestra de turistas, a pesar de sus recursos naturales idóneos, y el reconocimiento que tiene por la imagen del Greco.

Finalmente, el Panel de Experto indaga si este hecho se produce según la opinión de los expertos, y se obtiene que el atributo más valorado es el de la consideración de Toledo como Ciudad Patrimonio de la Humanidad, seguida de la importancia de los paisajes culturales. Dispone, así mismo, de la Catedral que sobresale por encima de los demás paisajes y vistas de Toledo, y advierten del desconocimiento que se tiene de la imagen de destino en general por los turistas. A tal efecto, el Panel de Experto procede a promocionar adecuadamente la imagen de la ciudad con propaganda institucional y empresarial por medio de Internet, las representaciones de los artistas y las descripciones literarias de la ciudad y de sus paisajes.

El paisaje como producto turístico en España tiene que dar a conocer la interpretación de los paisajes de Toledo, para comprender mejor su historia y problemas actuales; asimismo la puesta en valor de los paisajes toledanos por el turismo implican mejoras en su conservación y transmisión futuras. Se concluye que los paisajes de Toledo no están suficientemente promocionados desde la perspectiva turística, por la escasa información que se proyecta de la imagen de destino. A tal efecto, resulta esencial ofertar los paisajes culturales como imágenes de destino convenientemente interpretados y presentados al gran público a través de folletos, páginas webs y campañas publicitarias.

\section{Bibliografía}

Anato Martínez, Mercedes; Rivas Alfonso, Berta; González Agra, María A.

2010. "Paisaje e identidad cultural en la promoción de la imagen de Isla Margarita como destino turístico", en PASOS Revista de Turismo y Patrimonio Cultural, 1: 113-124.

Alcañiz Bigné, Enrique; Sánchez Garcia, Isabel; Sanz Blas, Silvia

2005. "Relationships among residents' image, evaluation of the stay and post-purchase behaviour", en Journal of Vacation Marketing, 11(4): 291-302.

Alcañiz Bigné, Enrique; Sanz Blas, Silvia

2001. "Tourism image, evaluation variables and after purchase behaviour: interrrelationship", en Tourism Management, 22(6): 607-616.

Campo, Sara \& Garau, Joan.

2008. "The influence of nationality on the generation of tourist satisfaction with a destination", en

Tourism Analysis, 13 (1): 81-92.

Comisión de las Comunidades Europeas

2007. Agenda para un turismo europeo sostenible y competitivo. Bruselas.

Chen, Ching-Fu, \& Tsai, Dungchun

2007. "How destination image and evaluative factors affect behavioural intentions?", Tourism Management, 28: 1115-1122.

Chi, Cristina, Geng-Quing Chi, \& Qu, Hailin

2008. "Examining the structural relationships of destination image, tourist satisfaction and destination loyalty: An integrated approach", Tourism Management, 29: 624-636.

De la Calle Vaquero, Manuel

2001. "Las ciudades históricas españolas como destinos turísticos. Patrimonio cultural y sistema de acogida local”, PH Boletín 36, Dossier: Turismo en ciudades históricas, pp.116-123. 
Duncan, James S.

1978. "The social construction of unreality: an interacionist approach to the tourist's cognition of environment”, en Humanystic Geography (D. Ley y M. Samuels, eds.), Londres: Ed. Croom Helm.

Embacher, J.; Buttle, F.

1989. "A Repertory Grid Analysis of Austria's Image as a Summer Vacation Destination" Journal of Travel Research, vol. 28 (3): 3-22.

EOI

2013. Turismo Cultural. Patrimonio, museos y empleabilidad, Turismo y Territorio. Madrid: Ministerio de Industria, Energía y Turismo, Escuela de Organización Industrial (EOI).

European Commission.

2014. Preferences of europeans towards tourism. Report, February. European Union: Flash Eurobarometer 392-TNS Political \& Social,

Eurostat.

2012. Tendencias turísticas. European Commission: Eurostat, disponible en http://ec.europa.eu/eurostat/ statistics-explained/index.php/Tourism_statistics/es. [Fecha de consulta 14 diciembre 2014].

Fornell, Claes; Johnson, Michael D.; Anderson, Eugene W.; Cha, Jaesun \& Bryant, Barbara Everitt

1996. The American customer satisfaction index: nature, purpose, and findings. The Journal of Marketing, 7-18.

Galí Espelt, Nuria; Donaire Benito, José Antonio

2006. "La imagen percibida por los turistas de la ciudad de Girona" revista IET Revista Instituto de Estudios Turísticos, nº 168 (2006), pp. 123-139, Secretaría General de Turismo.

Icomos

1999. Carta Internacional sobre Turismo Internacional. La gestión del turismo en los sitios con patrimonio cultural significativo. International Council on Monuments and Sites, disponible en http:// www.international.icomos.org/charters/tourism_sp.pdf. [Fecha de consulta 23 de noviembre 2014].

Ryu, Kisang; Han, Heesup and Kim, Tae-Hee

2008. "The Relationships among Overall Quick-Casual Restaurant Image, Perceived Value, Customer Satisfaction, and Behavioral Intentions," International Journal of Hospitality Management, Vol. 27: 459-469.

Rodríguez Oromendia, Ainhoa

2015. "Opinión del Experto sobre el paisaje de Toledo como recurso turístico en sí mismo", elaboración técnica de Ainhoa Rodríguez Oromendia en "Dinámicas comparadas para una gestión sostenible de los paisajes cultuales a través del turismo" (CULTURPAIS), Ref. CSO2011-24966, Ministerio de Ciencia e Innovación. Investigador principal: M. Antonio Zárate Martín.

Kozak, Metin; Rimmington, Mike

2000. "Tourist satisfaction with Mallorca, Spain as anoff-season holiday destination". Journal of Travel Research, 38: 260-269.

Lin, Hui; Fan, W., Wallace, L., \& Zhang, Z.

2007. January. An empirical study of web-based knowledge community success. In System Sciences, HICSS 2007. 40th Annual Hawaii International Conference on (pp. 178c-178c). IEEE.

López Olivares, Diego

2014. Los recursos turísticos. Evaluación, ordenación y planificación turística. Estudio de casos, Valencia:

Colección crónica, Tirant Humanidades.

Mccannell, Dean

1976. The tourist. A new theory of leisure class. Nueva York: Ed. Scho.

Mckercher, Bob; Cros, Hilary

2002. Cultural Tourism. The partnership between Tourism and Cultural Heritage management. Hawort

Hospitality Press.

Miranda Román, Guillermo

2006. "La participación del turismo en la modificación del paisaje cultural de Malinalco, Estado de Mexico”, PASOS. Revista de Turismo y Patrimonio Cultural, Vol. 4 (2). 201-211.

Melgosa Arcos, Franciso Jaier Coord.

2013. Turismo de Interior. Planificación, comercialización y experiencias. Madrid: Pirámide.

Pérez Cano, María Teresa

2001. "Turismo en las ciudades históricas: la ciudad sostenible", PH Boletín 36: 110-115. 
Pike, Steven; Ryan, Chuis

2004. "Destination Positioning Analysis Through a Comparison of Cognitive, Affective, and Conative

Perceptions". Journal of Travel Research. 42(4): 333-342.

Qu, Hailin; Kim, Lisa Hyunjung; Im, Holly Hyunjung

2011. "A model of destination branding: Integrating the concepts of the branding and destination image".

Tourism Management, 32(3): 465-476.

Rodríguez Archútegui, M.

2001. "El turista cultural y las ciudades históricas", PH Boletín 36, Dossier: Turismo en ciudades históricas, 36: 138-143.

Romero Moragas, Carlos

2001. "Ciudad, cultura y turismo: Calidad y Autenticidad", en PH Boletín 36: 100-109.

Rosenberg, L. J.; Czepiel, J. A.

1984. "A marketing approach for customer retention". Journal of consumer marketing, 1(2): 45-51.

Sanagustín Fons, Maria Victoria; Moseñe Fierro, José Antonio; Gómez Patiño, María

2011. Rural Tourism. A Sustainable Alternative. Applied Energy 88 (2): 551-557.

Sectur-Cestur

2002. Estudios Estratégicos de Viabilidad para el Segmento de Turismo Cultural en México. México:

Centro de Estudios Superiores de Turismo, Redes.

Tasci A.D.A.; Gartner, W.C.; Cavusgil, S.T.

2007. "Conceptualization and operationalization of destination image" en Journal of Hospitality and

Tourism Research, 31(2): 194-233.

Turespaña

2001. Turismo Cultural. Salamanca: Turespaña.

Zárate Martín, Manuel Antonio.

2012. "Paisaje, forma y turismo en ciudades históricas" en Estudios Geográficos, Vol. 73 (273): 657-694.

\section{Notas}

1 Investigación dentro del proyecto "Dinámicas comparadas para una gestión sostenible de los paisajes cultuales a través del turismo" (CULTURPAIS), Ref. CSO2011-24966, Ministerio de Ciencia e Innovación. Investigador principal: M. Antonio Zárate Martín. 